\title{
Studi Pengembangan Transformable Ride on Toys Berbahan Kayu sebagai Sarana Pembelajaran Gerak Motorik Balita
}

\author{
Irna Arlianti dan Bambang Tristiyono \\ Departemen Desain Produk, Fakultas Teknik Sipil dan Perencanaan, Institut Teknologi Sepuluh \\ Nopember (ITS) \\ e-mail:pakmbi@gmail.com
}

\begin{abstract}
Abstrak-Anak-anak terutama usia balita memiliki perilaku dan kebiasaan beraktivitas yang sangat kompleks. Bermain adalah salah satu media penyaluran kreativitas dan bakat anak yang berpengaruh pada perkembangan motorik anak, kondisi psikologi juga meningkatkan kadar interaksi sosial. Akan tetapi seiring perkembangan teknologi, stereotipe bermain di kalangan anakanak telah berubah. Dominasi penggunaan gadget di semua kalangan sudah menjamur kepada anak-anak. Ketika bermain tidak lagi harus menggerakkan badan dan berinteraksi dengan teman sebaya melainkan cukup berdiam diri dan asyik dengan dunia gadget. Hal ini tentu memprihatinkan mengingat anak harusnya dapat melakukan pembelajaran tumbuh kembang yang aktif seperti mengasah keterampilan motorik agar perkembangan fisik dan psikisnya optimal. Berdasarkan fenomena tersebut inovasi sarana bermain motorik perlu dilakukan. Salah satunya melalui sarana bermain ride on toys, yakni mainan yang dapat diduduki dan dikendarai. Seperti sepeda, adalah ride on toys yang familiar dengan anak yang juga mampu meningkatkan kadar interaksi sosial. Keberagaman dan kompleksitas gerak anak khususnya balita sebagai sasaran utama juga merupakan peluang inovasi desain ride on toys. Mengingat lifetime pada produk anak sangatlah pendek mendasari penulis mendesain transformable ride on toys, yakni dalam 1 unit ride on dapat diubah menjadi beberapa fungsi unit seperti push walker, balance bike, scooter dan lain sebagainya sesuai tahapan usia balita. Selain bertujuan menarik minat anak untuk beraktivitas fisik juga untuk menambah nilai jual produsen UKM lokal yang saat ini produksi mainan lebih didominasi impor mainan plastik. Berdasarkan kondisi tersebut memberdayakan UKM mainan kayu lokal juga perlu dilakukan mengingat ride on toys lokal masih berupa tunggangan kuda kayu yang memiliki nilai jual rendah.
\end{abstract}

Kata Kunci-Ride on Toys, Sepeda Kayu an, Transformable.

\section{PENDAHULUAN}

$\mathrm{K}$ EBERAGAMAN aktivitas anak - anak menjadi salah satu faktor penting dalam tumbuh kembang anak. Anak balita memiliki beberapa tahapan tumbuh kembang dimana dua di antaranya adalah fase yang penting yakni fase anak (umur 1 - 3tahun) dan fase bermain (umur $3-6$ tahun) atau biasa disebut play age. Pada fase tersebut diperlukan pembelajaran berupa sarana bermain untuk menunjang kecerdasan anak. Akan tetapi tren penggunaan gadget terutama di kalangan anak usia dini menjadi hal yang patut diwaspadai tidak hanya dampak internal namun terdapat dampak sosial seperti mengurangi kadar interaksi sosial. Padahal, pada anak usia dini interaksi sosial memanglah sangat dibutuhkan karena anak nantinya akan diajarkan bagaimana hidup bermasyarakat, lalu anak juga akan diajarkan berbagai peran yang nantinya akan menjadi identifikasi dirinya, selain itu pula saat melakukan interasi sosial anak akan memperoleh berbagai informasi yang ada disekitarnya [1]. Selain itu penggunaan gadget juga mempengaruhi kesehatan anak. Frekuensi kegiatan 'berdiam diri' dengan atribut bermain menggunakan gadget juga kurang baik untuk pertumbuhan tulang anak. Berdasarkan fenomena tersebut dibutuhkan sarana bermain yang mengandalkan aktivitas fisik salah satunya melalui stimulus gerakan motorik yang merupakan kemampuan dasar anak dalam beraktivitas. Berbagai permainan motorik baik halus dan kasar sudah banyak ditawarkan. Salah satu pembelajaran yang dapat diberikan yakni melalui sarana bermain ride on toys, mainan yang dapat diduduki dan dikendarai. Mainan ini merupakan peluang karena berdasarkan fenomena serta observasi lapangan bahwa anak - anak tidak asing dan menggemari beraktivitas dengan ride on toys contohnya sepeda.

Akan tetapi saat ini masyarakat kalangan menengah atas lebih cenderung menjadi konsumen mainan pabrikan impor plastik yang lebih modern dengan standarisasi kualitas yang lebih terjamin. Hal tersebut menjadi wajar sebab mayoritas ride on toys buatan Indonesia berupa tunggangan kuda berbahan kayu yang hampir sama desainnya setiap tahun dengan nilai jual rendah[2].

Inovasi desain perlu dilakukan agar mampu menghasilkan produk mainan dalam negeri yang bersaing dengan produk impor. Kompleksnya gerak motorik anak dalam beraktivitas [3], menjadi landasan utama dalam melakukan pengembangan desain ride on toys yang dapat mengakomodasi perkembangan gerak motorik anak secara komperhensif melalui 1 unit mainan yang dapat diubah menjadi 3 fungsi.

\section{METODE PENELITIAN}

\section{A. Tahap Pengumpulan Data}

\section{1) Deep Interview}

Pada tahap ini dilakukan pengambilan data primer maupun sekunder. Data primer diambil melalui deep interview dengan orang tua anak balita untuk mengetahui pertimbangan dan minat dalam memilih mainan anak. Hal ini bertujuan untuk mengetahui ragam mainan yang dimiliki, kebutuhan stimulus 
tumbuh kembang motorik serta daya beli konsumen. Deep interview dilakukan pada 3 orang tua yang memiiki anak balita usia 2, 3 dan 4 tahun.

Deep interview kedua dilakukan pada IKM kayu lokal yakni industri kayu Pasuruan untuk mengetahui kemampuan produksi, sumber daya kayu, dan peralatan yang dimiliki.

\section{2) Observasi Lapangan}

Tahap pengambilan data berikutnya yakni melakukan observasi lapangan pada anak usia 2, 3, dan 4 tahun untuk mengetahui rincian aktivitas anak selama bermain di rumah, kebiasaan anak dan perlakuan anak terhadap mainan. Selain itu juga untuk mengetahui jenis aktivitas fisik sederhana anak yang dilakukan setiap hari serta frekuensinya karena keberagaman aktivtas anak. Selanjutnya hasil observasi digunakan untuk mengetahui kebutuhan transformasi ride on toys yang sesuai dengan tingkatan usia balita. Observasi dilakukan pada anak berbeda gender dan tahapan usia.

\section{3) Affinity Diagram}

Metode berikutnya yaitu membuat affinity diagram Kawakita, penindakan lebih lanjut dari metode - metode sebelumnya. Affinity diagram bertujuan untuk mengelompokkan masalah dan fenomena yang ada didapat dari hasil pengumpulan data sebelumnya. Selanjutnya dari semua isu permasalahan yang didapatkan dikelompokkan sesuai kata kunci yang sesuai sehingga membantu dalam pembuatan konsep desain.

Tahap pengumpulan data pendukung lainnya adalah pengambilan data sekunder yakni literatur dari jurnal, majalah, artikel dari web resmi, dan studi sebelumnya yang berkaitan guna menunjang vaiditas data primer yang dilakukan sebelumnya.

\section{B. Eksplorasi Ide}

Brainstorming Sketsa- Hasil pengumpulan data sekunder dan primer diolah dengan melakukan brainstroming sketsa untuk mencari gambaran umum bentuk transformasi secara umum sesuai konsep desain.

\section{Pemilihan Alternatif Desain}

Hasil eksplorasi ide selanjutnya dikerucutkan ke dalam beberapa alternative desain Beberapa alternative desain kemudian dilakukan pemilihan alternative desain berdasarkan indikator yang sesuai dan mengacu pada hasil riset dan perancangan.

\section{Studi dan Analisis Desain}

Alternatif desain terpilih kemudian dikembangkan lebih detail dengan support studi dan analisis desain yang sesuai dengan konsep desain seperti aspek teknis, bentuk, dll.

\section{E. Pengembangan Desain}

\section{1) Studi Model}

Metode selanjutnya yakni melakukan studi mode 1:5 untuk mencari kesesuaian bentuk dan transformasi lebih kongkret sehingga dapat menghasilkan batasan konfigurasi bentuk. Selain itu juga bertujuan menemukan sambungan (joints) antar parts yang tepat menggunakan material kayu balsa dan tripleks.

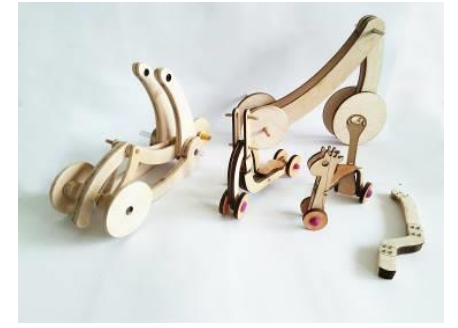

Gambar 1. Studi Model.

\section{2) Digital Modelling}

Alternatif desain terpilih selanjutnya disimulasikan dengan digital modelling untuk menemukan alternatif per part nya untuk menemukan desain akhir.

\section{F. Prototyping}

Desain akhir yang telah sesuai diwujudkan dalam bentuk prototype berskala 1 : 1 menggunakan material sebenarnya yakni kayu jati $90 \%$ dan $10 \%$ spare parts pendukung.

\section{G. Usability Testing}

Tahap terakhir melakukan pengujian prototype menggunakan usability testing, yakni mencobakan kepada target user dalam hal ini anak - anak untuk mengetahui kekuatan, ketahanan beban dan kenyamanan.

\section{KONSEP DAN ANALISIS}

\section{A. Konsep Desain}

Ide dan percobaan yang telah dilakukan selanjutnya diolah untuk menemukan konsep desain melalui brainstorming sebagai berikut :

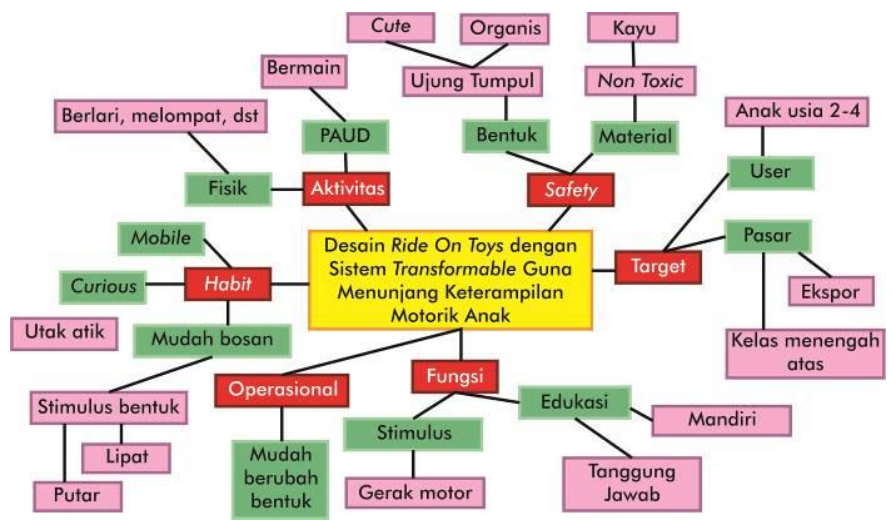

Gambar 2. Brainstorming Konsep Desain.

Brainstorming tersebut menghasilkan 3 kata kunci dalam konsep desain, antara lain :

1. Fun \& Playful

Menciptakan pola permainan yang variatif sehingga anak tidak mudah bosan.

2. Cute Kiddy

Mengadaptasi bentuk yang lucu untuk menarik minat anak seperti morfologi berbagai hewan sebagai impresi kanak - kanak dan pengenalan terhadap jenis hewan.

3. Eco Friendly

Menggunakan material mainan yang ramah lingkungan yakni kayu yang bersifat non-toxic dan aman bagi mainan anak. 
Konsep desain merupakan acuan dalam menentukan analisis yang sesuai dan menghasilkan eksplorasi part.

\section{B. Studi Gerak Motorik Balita}

Hasil dari observasi lapangan pada anak balita usia 2, 3 dan 4 tahun menunjukkan bahwa terdapat kompleksitas gerak motorik anak seiring dengan bertambahnya usia.

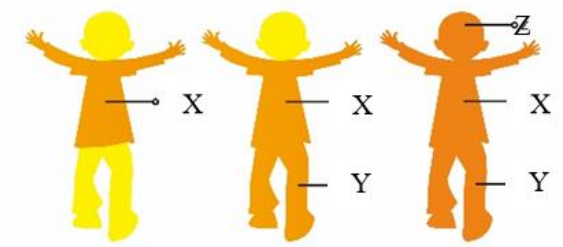

Anak usia 2 tahun Anak usia 3 tahun Anak usia 4 tahun

(X) : angg. tubuh (X) : angg. tubuh aktif (X) : angg. tubuh aktif aktif (Y) : angg. tubuh aktif (Y) : angg. tubuh aktif

(Z) : angg. tubuh aktif

Gambar 3. Peningkatan Gerak Fisik Balita.

Setiap jenjang usia memiliki ciri keterampilan fisik motorik yang berbeda dari sederhana hingga kompleks. Berikut diagram penggolongan keterampilan motorik anak berdasarkan hasil observasi lapangan yang diolah dalam analisis aktivitas.

Berdasarkan hasil penelitian di atas, ditemukan alternatif bentuk transformasi yang memungkinkan dalam pengembangan desain transformable ride on toys :

Tabel 1.

Alternatif Bentuk Transformasi berdasarkan Tipe Gerak Fisik

\begin{tabular}{|c|c|c|c|}
\hline Usia & AktivitasFisik & Tipe Gerak Fisik & $\begin{array}{c}\text { Bentuk } \\
\text { transformasi } \\
\text { yang } \\
\text { memungkinkan } \\
\end{array}$ \\
\hline 2 tahun & $\begin{array}{l}\text { - Melempar } \\
\text { - Mendorong }\end{array}$ & $\begin{array}{l}\text { Keterampilan Non } \\
\text { Lokomotor }\end{array}$ & $\begin{array}{l}\text { - Push walker } \\
\text { - Rocking horse }\end{array}$ \\
\hline 3 tahun & $\begin{array}{l}\text { - Melempar } \\
\text { - Melompat } \\
\text { - Berlari } \\
\text { - Tarik-dorong }\end{array}$ & $\begin{array}{l}\text { Keterampilan Non } \\
\text { Lokomotor dan } \\
\text { Lokomotor }\end{array}$ & $\begin{array}{l}\text { - Push walker } \\
\text { - Rocking horse } \\
\text { - Toddler bike } \\
\text { (sepedatanpa } \\
\text { pedal) }\end{array}$ \\
\hline 4 tahun & $\begin{array}{l}\text { - Mengayuh } \\
\text { - Berlari }\end{array}$ & $\begin{array}{l}\text { Keterampilan } \\
\text { Lokomotor dan } \\
\text { Manipulatif }\end{array}$ & $\begin{array}{l}\text { - Toddler bike } \\
\text { (sepedatanpa } \\
\text { pedal) } \\
\text { - Otoped / } \\
\text { Scooter Toy }\end{array}$ \\
\hline
\end{tabular}

\section{Analisis Transformable Design}

Tahap selanjutnya mencari kesatuan bentuk yang diolah dalam analisis bentuk dan geometri berdasarkan hasil studi model yang menghasilkan batasan konfigurasi bentuk sebagai berikut:
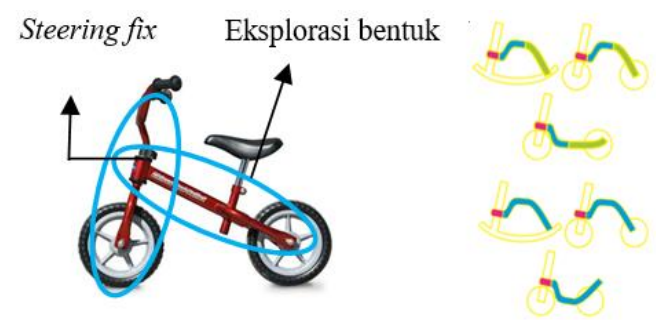

Gambar 4. Eksplorasi Bentuk Transformasi.

\section{Analisis Geometri}

Hasil dari eksplorasi bentuk rangka secara umum diolah dalam analisis geometri yakni mencari geometri dasar rangka utama berdasarkan titik kritis pada eksisting ride on toys umum yakni sepeda.

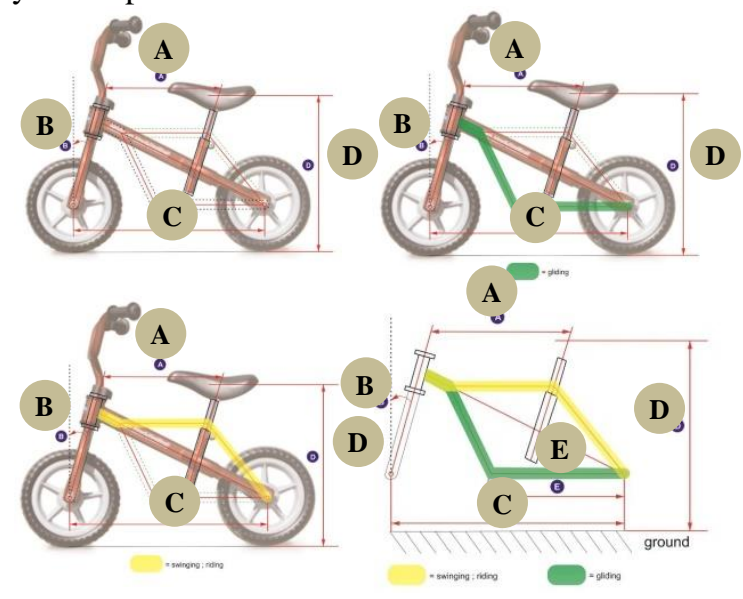

Gambar 5. Hasil Transformasi Geometri Rangka Utama.

Dari pengolahan geometri di atas didapatkan 2 mekanisme rotasi pada gambar yang bertanda kuning dan hijau. Rangka berwarna kuning menghasilkan 2 fase transformasi yakni swinging berupa fungsi tunggangan kuda dan riding berupa sepeda tanpa pedal (balance bike). Rangka berwarna hijau menghasilkan 1 fase transformasi yakni fase gliding berupa skuter atau otoped.

Berikut ukuran dan titik kritis pembentuk rangka ride on toys :

Tabel 2.

Ukuran Pembentuk Rangka

\begin{tabular}{clc}
\hline \hline Kode & \multicolumn{1}{c}{ Titik Kritis } & Ukuran (mm) \\
\hline \multirow{2}{*}{ A } & Jarak sadel dengan handle & 371 \\
& bars & $12^{0}$ \\
B & Sudut kemiringan steering & 600 \\
C & Wheel base & 329 \\
D & Ketinggian sadel dari tanah & 265 \\
E & Panjang rangka alas skuter & \\
\hline \hline
\end{tabular}

\section{Analisis Material}

Ketika geometri bentuk transformasi sudah didapatkan, kemudian dilakukan analisis material untuk menentukan jenis kayu yang sesuai untuk digunakan berdasarkan properties kayu yang didapat dari Lembaga Pusat Penyelidikan Kehutanan dan menghitung kekuatannya.

Tabel 3.

Spesifikasi Kayu berdasarkan Kelas Kuat

\begin{tabular}{ccccc}
\hline \hline JenisKayu & KelasKuat & $\begin{array}{c}\text { Berat Jenis } \\
\text { Kering } \\
\text { Udara }\end{array}$ & $\begin{array}{c}\text { Kuat Lentur } \\
\mathbf{( \mathbf { T } )} \\
\left(\mathbf{K g} / \mathbf{C m}^{\mathbf{2}}\right)\end{array}$ & $\begin{array}{c}\text { Kuat Desak } \\
(\mathbf{e})\left(\mathbf{K g} / \mathbf{C m}^{\mathbf{2}}\right)\end{array}$ \\
\hline Jati & I & $\geq 0,90$ & $\geq 1100$ & $\geq 650$ \\
$\begin{array}{c}\text { Mahoni, } \\
\text { Mindi, }\end{array}$ & II & $0,90-0,60$ & $1100-725$ & $650-425$ \\
$\begin{array}{c}\text { Meranti, } \\
\text { Keruing }\end{array}$ & & & & \\
$\begin{array}{c}\text { Mahoni, } \\
\text { Mindi }\end{array}$ & III & $0,60-0,40$ & $725-500$ & $425-300$ \\
Meranti & IV & $0,40-0,30$ & $500-360$ & $300-215$ \\
\hline
\end{tabular}




\begin{tabular}{c|c|ccc}
\hline Sengon & V & $\leq 0,30$ & $\leq 360$ & $\leq 215$ \\
\hline \hline \multicolumn{1}{c}{$\begin{array}{c}\text { Kelas Kuat I } \\
\text { (Jati) }\end{array}$} & $\begin{array}{c}\text { Kelas Kuat II } \\
\text { (Meranti } \\
\text { Kuning) }\end{array}$ & $\begin{array}{c}\text { Kelas Kuat III } \\
\text { (Keruing) }\end{array}$ & $\begin{array}{c}\text { Kelas Kuat IV } \\
\text { (Mahoni) }\end{array}$ & $\begin{array}{c}\text { Kelas Kuat V } \\
\text { (Sengon) }\end{array}$
\end{tabular}

Gambar 6. Jenis Kayu berdasarkan Kelas Kuat.

Kelas kuat kayu ditentukan melalui kualitas kayu, keawetan, dan harga.

Tabel 4.

Pemilihan Jenis Kayu

\begin{tabular}{|c|c|c|c|c|c|c|c|c|c|c|c|c|}
\hline \multirow[b]{2}{*}{$\begin{array}{l}\mathbf{N} \\
\mathbf{o}\end{array}$} & \multicolumn{2}{|l|}{ Parameter } & \multicolumn{2}{|c|}{$\begin{array}{l}\text { Kelas I } \\
\boldsymbol{R}\end{array}$} & \multicolumn{2}{|c|}{ Kelas II } & \multicolumn{2}{|c|}{ Kelas III } & \multicolumn{2}{|c|}{ Kelas IV } & \multicolumn{2}{|c|}{ " Kelas V } \\
\hline & Item & $\mathbf{W}$ & $\begin{array}{l}R \\
a t \\
e s\end{array}$ & $\begin{array}{l}\text { To } \\
\text { tal }\end{array}$ & $\begin{array}{l}\text { Ra } \\
\text { tes }\end{array}$ & $\begin{array}{l}\text { To } \\
\text { tal }\end{array}$ & $\begin{array}{l}\text { Ra } \\
\text { tes }\end{array}$ & $\begin{array}{l}\text { To } \\
\text { tal }\end{array}$ & $\begin{array}{l}\text { Ra } \\
\text { tes }\end{array}$ & $\begin{array}{l}\text { To } \\
\text { tal }\end{array}$ & $\begin{array}{l}\text { Ra } \\
\text { tes }\end{array}$ & $\begin{array}{l}\text { To } \\
\text { tal }\end{array}$ \\
\hline 1 & $\begin{array}{l}\text { Kekuatan } \\
\text { struktur }\end{array}$ & $\begin{array}{c}0 \\
6\end{array}$ & 4 & $\begin{array}{l}2, \\
4\end{array}$ & 3 & $\begin{array}{l}1, \\
8\end{array}$ & 3 & $\begin{array}{l}1, \\
8\end{array}$ & 2 & $\begin{array}{l}1, \\
2\end{array}$ & 1 & $\begin{array}{l}0, \\
6\end{array}$ \\
\hline 2 & Keawetan & $\begin{array}{l}0, \\
3\end{array}$ & 4 & $\begin{array}{l}1, \\
2\end{array}$ & 3 & $\begin{array}{l}0 \\
9\end{array}$ & 2 & $\begin{array}{l}0, \\
6\end{array}$ & 2 & $\begin{array}{c}0 \\
6\end{array}$ & 1 & $\begin{array}{l}0, \\
3\end{array}$ \\
\hline 3 & Harga & $\begin{array}{c}0, \\
1\end{array}$ & 2 & $\begin{array}{l}0, \\
2\end{array}$ & 3 & $\begin{array}{r}0, \\
3\end{array}$ & 3 & $\begin{array}{c}0, \\
3\end{array}$ & 4 & $\begin{array}{l}0, \\
4\end{array}$ & 4 & $\begin{array}{l}0, \\
4\end{array}$ \\
\hline & Total & 1 & & $\begin{array}{l}3, \\
8\end{array}$ & & $\begin{array}{l}3, \\
0\end{array}$ & & $\begin{array}{l}2 \\
7 \\
\end{array}$ & & $\begin{array}{l}2, \\
2\end{array}$ & & $\begin{array}{l}1, \\
3\end{array}$ \\
\hline
\end{tabular}

Deskripsi Parameter :

1. Kekuatan Struktur $(0,6)$

Komponen paling penting dalam pemilihan jenis kayu adalah kekuatan sehingga bernilai 0,6 karena berpengaruh pada keberhasilan sistem transformable. Makin kuat strukturnya, dengan serat yang makin rapat maka jenis kayu paling kuat. Oleh karena itu kayu kelas I memiliki rates paling besar (4) dan menurun nilainya hingga kelas $\mathrm{V}$.

2. Keawetan $(0,3)$

Parameter selanjutnya sebagai urutan kedua dengan poin 0,3 adalah indikator kedua yang berpengaruh pada lifetime produk. Makin awet jenis kayu maka nilai makin besar hal ini ditunjukkan pada kayu kelas I dengan rates paling tinggi (4) contohnya kayu jati dengan umur kayu relatif panjang.

3. Harga $(0,1)$

Harga menjadi urutan paling akhir dengan poin terkecil 0,1 karena bukan merupakan prioritas dalam desain. Target klasifikasi produk merupakan premium product dengan segmen kelas menengah atas sehingga desain membutuhkan material dengan kualitas paling baik akan tetapi berdasarkan data memiliki harga paling mahal sehingga dipilih parameter harga paling kecil di kayu kelas I yakni bernilai 2 .

Kesimpulan :

Berdasarkan hasil analisis material dipilih jenis kayu kelas I yang bernilai paling tinggi berdasarkan parameter yang sesuai. Jenis kayu kelas I yang digunakan adalah kayu jati dengan properties kayu paling sesuai.

\section{HASIL DAN PEMBAHASAN}

\section{A. Eksplorasi Ide}

Pencarian ide awal dengan brainstorming sketsa untuk menemukan transformasi awal secara umum dan morfologi bentuk yang sesuai konsep desain.
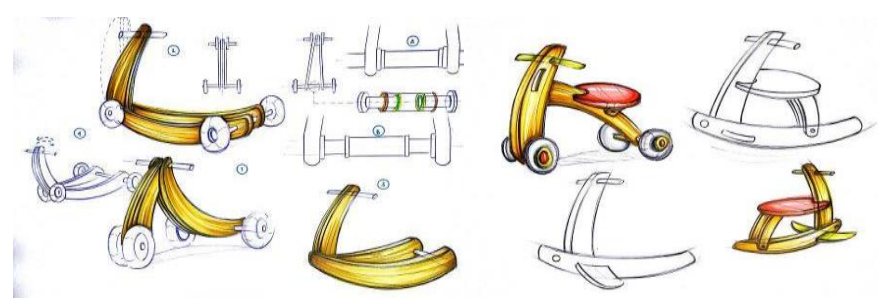

Gambar 7. BrainstromiOng Sketsa Ide.

Hasi leksplorasi ide selanjutnya dikerucutkan ke dalam beberapa alternative desain. Berikut beberapa eksplorasi ide yang menjadi alternatif desain:

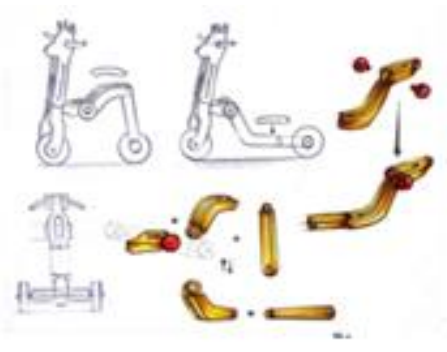

Alt 1

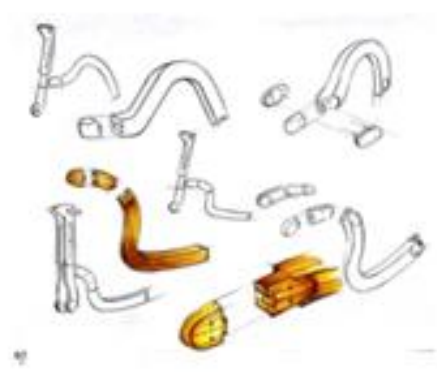

Alt 2

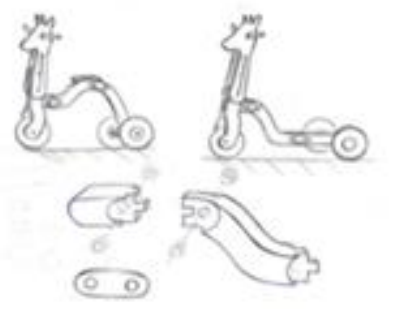

Alt 3

Gambar 8. Alternatif Desain.

\section{B. Pemilihan Alternatif Desain}

Beberapa alternatif desain kemudian dilakukan pemilihan alternatif desain berdasarkan indikator yang sesuai dan mengacu pada hasi riset dan perancangan.

Tabel 5.

Pemilihan Alternatif Desain

\begin{tabular}{|c|c|c|c|c|c|c|c|c|c|}
\hline \multirow{2}{*}{ No } & \multicolumn{2}{|c|}{ Parameter } & \multirow[b]{2}{*}{ Deskripsi } & \multicolumn{2}{|c|}{ Alt 1} & \multicolumn{2}{|c|}{ Alt 2} & \multicolumn{2}{|c|}{ Alt 3} \\
\hline & Item & $\mathbf{W}$ & & Rates & Total & Rates & Total & Rates & Total \\
\hline 1 & $\begin{array}{l}\text { Kekuatan } \\
\text { struktur }\end{array}$ & 0,7 & $\begin{array}{l}\text { Struktur } \\
\text { rangka }\end{array}$ & 1 & 0,7 & 2 & 1,4 & 3 & 2,1 \\
\hline 2 & $\begin{array}{l}\text { Kemudahan } \\
\text { transformasi }\end{array}$ & 0,2 & $\begin{array}{l}\text { Mekanisme } \\
\text { operasional }\end{array}$ & 3 & 0,6 & 1 & 0,6 & 2 & 0,4 \\
\hline 3 & $\begin{array}{l}\text { Kemudahan } \\
\text { produksi }\end{array}$ & 0,1 & $\begin{array}{l}\text { Produsen } \\
\text { UKM }\end{array}$ & 3 & 0,3 & 2 & 0,3 & 2 & 0,2 \\
\hline & Total & 1 & & & 1,6 & & 2,3 & & 2,7 \\
\hline
\end{tabular}


Rentang rates penilaian dari angka 1-5 mengindikasikan nilai dari setiap alternatif desain yang mengacu pada parameter item berdasarkan sumber :

\section{1) Kekuatan struktur $(0,7)$}

Struktur rangka utama merupakan komponen yang paling utama dalam mendesain ride on toys yang menentukan keberhasilan perwujudan sistem transformable. Hal ini karena struktur rangka dipengaruhi oleh distribusi beban dan gaya pengendara yang dianalisis dalam analisis geometri. Apabila rangka memiliki jumlah part lepas pasang paling sedikit dan tidak mengenai titik kritis, maka nilai rates semakin baik.

2) Kemudahan transformasi $(0,2)$

Komponen penting prioritas kedua adalah kemudahan transformasi yang mengacu pada letak sambungan lepas pasang, jumlah sambungan, spare parts pendukung sambungan. Semakin jauh letak sambungan dengan titik kritis maka penilaian semakin baik, semakin sedikit jumlah sambungan dan semakin cepat pengguna dalam operasional lepas pasang maka nilai semakin baik.

3) Kemudahan produksi $(0,1)$

Indikator berikut memiliki poin paling rendah karena merupakan prioritas paling terakhir. Hal ini disebabkan desain yang dihasilkan bersifat custom design dan tidak berorientasi pada produksi masal.

Deskripsi Rates :

Alternatif 1

Pada indikator kekuatan struktur, rates bernilai 1 karena sambungan transformasi terletak di tengah rangka dan rawan patah ketika dikenai beban. Untuk indikator kemudahan transformasi, rates bernilai 3 karena sambungan yang digunakan memiliki kemudahan operasional karena tidak perlu alat bantu tambahan saat lepas pasang. Sedangkan untuk kemudahan produksi bernilai paling besar yakni 3 karena tidak membutuhkan presisi tinggi.

Alternatif 2

Rates bernilai 2 pada kekuatan struktur karena memiliki jenis sambungan yang lebih kuat dari alternatif 1 dan tidak terlalu mendekati titik kritis ride on toys yakni pada tengah rangka. Pada indikator kemudahan transformasi alternatif 2 memiliki rates bernilai 1 karena membutuhkan extension part saat berubah dari fase bentuk 1 ke lainnya sehingga kurang efektif. Untuk indikator kemudahan produksi bernilai 2 karena menggunakan jenis sambungan yang sudah banyak dikerjakan UKM yakni mortise tennon joint sehingga lebih familiar.

Alternatif 3

Pada alternatif 3, memiliki kekuatan struktur paling baik sehingga rates bernilai 3 . Hal ini karena bentuk sambungan memiliki struktur paling kuat yang disupport dengan sambungan pelat. Untuk kemudahan transformasi memiliki rates bernilai 2 karena cukup mudah ketika ditransformasi tanpa membutuhkan extension part.

Berdasarkan ketiga alternatif dipilih alternatif 3 dengan total nilai paling besar. Kemudian alternatif terpilih dieksplorasi lebih lanjut dalam pengembangan desain.

\section{Pengembangan Desain}

\section{1) Eksplorasi Part Rangka}

Terdapat beberapa eksplorasi part rangka berdasarkan jumlah titik lepas pasang yang mengacu pada kekuatan struktur, ketahanan beban, kemampuan produksi, dan pola potong bahan, antara lain sebagai berikut :
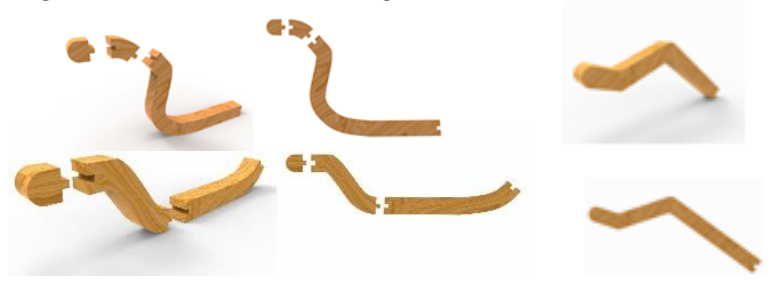

Gambar 9. Eksplorasi Part Rangka.

\section{2) Eksplorasi Part Sambungan}

Eksplorasi sambungan juga dilakukan untuk mengetahui mekanisme rotasi transformasi yang paling efektif dan dapat diproduksi kelas UKM, antara lain :
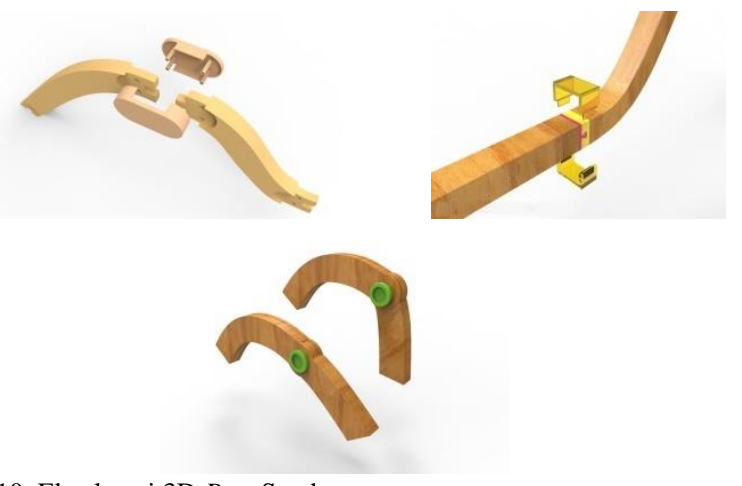

Gambar 10. Eksplorasi 3D Part Sambungan.

\section{a. Eksplorasi Part Steering}

Bagian steering juga merupakan komponen penting yang dapat dijadikan peluang untuk menghasilkan faktor interest anak melalui morfologi bentuk berbagai hewan seusia konsep cute kiddy, antara lain sebagai berikut :
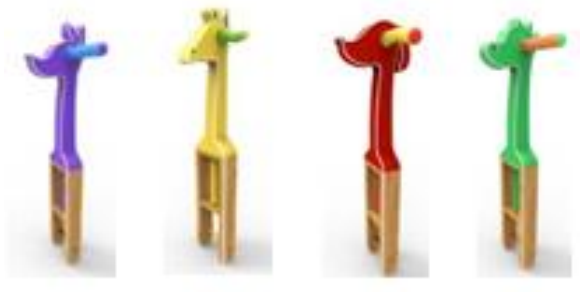

Gambar11. Eksplorasi Part Steering.

\section{b. Eksplorasi Part Wheelholder}

Part wheelholder adalah bagian sambungan roda belakang yang merupakan salah satu titik tumpu beban saat operasional selain bagian dudukan. Oleh karena itu dilakukan eksplorasi berdasarkan bentuk eksisting sepeda dengan memperhatikan kebutuhan transformasi, operasional, dan kemudahan produksi.
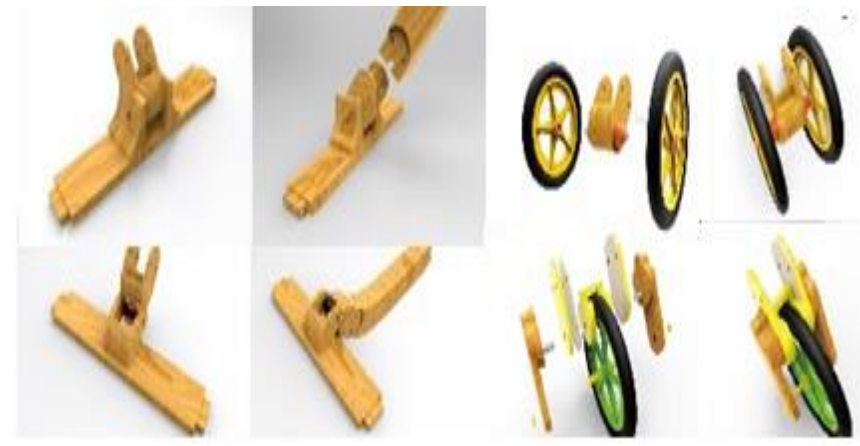

Gambar12. Eksplorasi Part Wheelholder. 


\section{Desain Akhir}

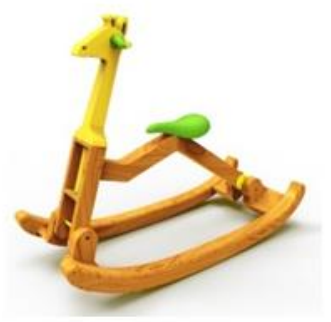

(a)

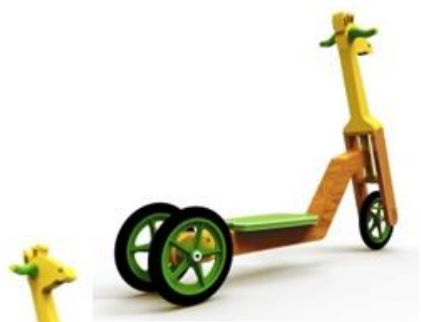

(b) (c)

Gambar14. Desain Akhir (a) Swinging; (b) Riding ; (c) Gliding.

\section{E. Usability Testing}

Desain terpilih yang dilakukan usability testing kepada anak balita untuk mengetahui ketahanan beban, struktur, dan kenyamanan.
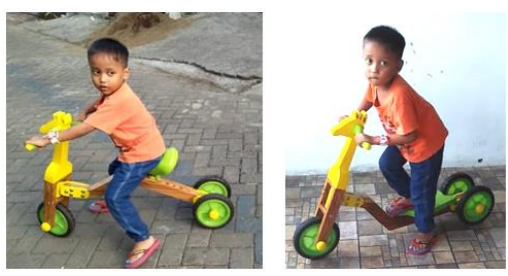

Gambar 15. Prototipe Desain Akhir.

Hasil usability testing :

1. Pada desain akhir, rangka yang dikembangkan dapat menahan beban anak persentil paling maksimal $+/-20 \mathrm{~kg}$.

2. Sambungan yang digunakan juga mampu mentransformasi dengan presisi untuk setiap perubahan fase ride on toys.

3. Bagian wheel holder telah diperbaiki dengan mempersempit jarak as roda belakang sehingga kaki anak sudah tidak terbentur saat bermain skuter (fase gliding).

\section{KESIMPULAN}

Dalam mendesain transformable ride on toys yakni sarana bermain pendukung pembelajaran gerak motorik secara komperhensif terdapat beberapa hal yang perlu dipertimbangkan antara lain :

1. Desain transformable ride on toys harus memiliki kemudahan transformasi dengan komposisi part yang tidak terlalu banyak sehingga memudahkan distribusi dan penyimpanan di dalam rumah.

2. Konstruksi rangka bodi utama harus kokoh sehingga dibutuhkan material dengan struktur yang kuat dan rigid.

3. Mengembangkan bentuk transformasi ride on toys yang menarik minat anak dan mengakomodasi gerak motorik secara komperhensif.

Dari beberapa hal yang telah disebutkan, sesuatu yang paling mendasar yaitu terdapat titik kritis pada rangka utama sepeda sebagai eksisting desain yang tidak boleh dikenai sambungan seperti pada bagian tengah rangka. Selain itu, diperlukan minimalisasi sambungan sehingga tidak memotong banyak bahan yang dapat mengurangi kekuatan konstruksi rangka utama.

\section{DAFTAR PUSTAKA}

[1] W. NOVITASARI and N. Khotimah, "DAMPAK PENGGUNAAN GADGET TERHADAP INTERKSI SOSIAL ANAK USIA 5-6 TAHUN," PAUD Teratai, vol. 5, no. 3, 2016.

[2] YAYASAN LEMBAGA KONSUMEN INDONESIA, "Keamanan Mainan Edukasi Anak yang Beredar di Pasaran - Yayasan Lembaga Konsumen Indonesia." [Online]. Available: http://ylki.or.id/2012/01/keamanan-mainan-edukasi-anak-yang-beredardi-pasaran/. [Accessed: 13-Mar-2018].

[3] J. Santrock, Life Span Development. New York: McGraw-Hill Companies, 2007. 